\title{
Microstructural analysis of collapsible soil before and after collapse and with loading and unloading cycle
}

\author{
Ilton Alves ${ }^{1 *}$, Larissa Costa $^{2}$, Antônio Antonino ${ }^{2}$, Licia Costa $^{1}$ and Silvio Ferreira ${ }^{1}$ \\ ${ }^{1}$ UFPE, Civil Engineering Department, 50740-550 Av. da Arquitetura, Brazil \\ ${ }^{2}$ UFPE, Nuclear Energy Department, 50740-545 Av. Professor Luiz Freire, 1000, Brazil
}

\begin{abstract}
Aspects related to the volume variation of collapsible soils due to the change in water content are influenced by several factors, including the microstructure. The microstructure analysis of the soil is especially important in order to understand these aspects. This paper shows a comparative analysis of the microstructure of three samples of a collapsible Yellowish Red Sand from the district of Petrolina (northeast of Brazil), carried out by means of two techniques: Scanning Electron Microscope (SEM) and X-Ray Computed Tomography. Three undisturbed sample were used: the first no pressure was applied, in the second an one-dimensional compression of $160 \mathrm{kPa}$ was applied and then the sample was unloaded, and in the third, between the compression and decompression, the sample was flooded with the occurrence of structural collapse. In the first sample, the soil microstructure is a matrix with a predominance of grains of sand clothed with iluvial clay with interconnected pores that confers instability. The second sample showed a reduction in macropores after loading. In the third sample the structure remained with a simple packing arrangement, however, there is a greater packing between the grains, in addition to the wetting-induced softening of the clay particles that fill in the voids. It is also observed, through the radiodensity analysis that at the top and bottom of the second and third samples there was an increase in volume due to the stress relief that is not observed in the central section of the samples. The two microstructure analysis techniques are complementary.
\end{abstract}

\section{Introduction}

The study of the behavior of soils has had many advances due to the development of techniques and equipment capable of carrying out studies on increasingly smaller scales. This greatly improved the understanding of the behavior of metastable soils. The study of mechanism of collapse phenomenon showed that it was due the local failure between grain or peds and was best described in terms of two separated effective stresses, applied stress and suction (Barden et al. 1973 [01]).

Collapsible soils are quite problematic, as they develop large variations in volume due to reduction of suction. The existence of a collapse fabric is a condition for the soil to be collapsible (Schwartz, 1985 [02]). Vilar and Rodrigues (2015) [03] carried out a survey of the collapsible soils published in different places around the world, and it seemed that $36 \%$ of the analyzed soils were sandy, $38 \%$ silty and $26 \%$ clayey. Thus, the mechanism of collapse applies to different types of soils, not just in sands.

There is occurrence of collapsible soil in all regions of Brazil, Fig 1 (Freitas, 2017 [04]). The tropical region influences the origin of collapsible soil (Ferreira, 1995 [05]). They are originated from pedogenic evolutions of residual or transported soils (Vargas, 1978 [06]). The occurrence of collapsible soil can be correlated with geology information, pedologic and region's climate. Silva (2003) [07] made a map of susceptibility for the collapse soil in the city of Petrolina. This study revealed that the development of urban area occurred in regions of median to high susceptibility.

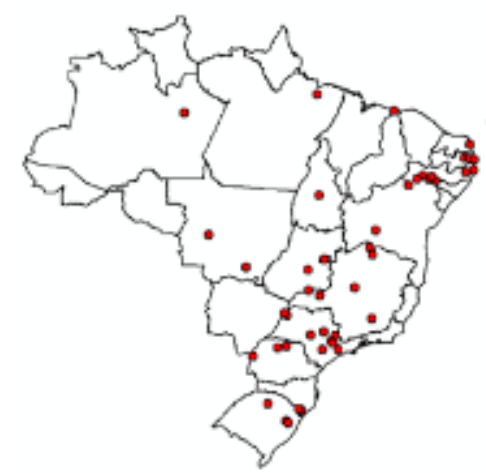

Fig. 1. Occurrence of collapsible soils in Brazil. From: Freitas (2017) [04].

For most engineering analysis and design the soil is simplified as a continuum mass, but it is known that strength, compressibility, and permeability depend on the size, shape, and arrangement of particles. Due to computational advances and technologic development to

\footnotetext{
Corresponding author: iltonalves@gmail.com
} 
characterize microscopic properties of soils, new theories of particulate mechanics are now becoming available.

In this paper, the soil fabric from Petrolina is analyzed in three situations: undisturbed, disturbed with a temporally load and after the collapse. The arrangement of the particle was observed with Scanning Electron Microscope (SEM) and X-Ray Computed Tomography (CT).

\section{Structures of collapsible soil}

Soil formation is result of its geological history. Rodrigues and Lollo (2008) [08] described four distinct processes of collapsible soil's formation: weathering of the matrix rock (residual); by the action of the winds (wind); by the action of water (alluvium and colluvium) and material compressed. McGrown and Collins (1975) [09] classified microfabric forms for expansion and collapsible soil in three types: elementary particle arrangement; 2 particle assemblage; 3 pore spaces. Figure 2 shows a schematic interpretation of this units.

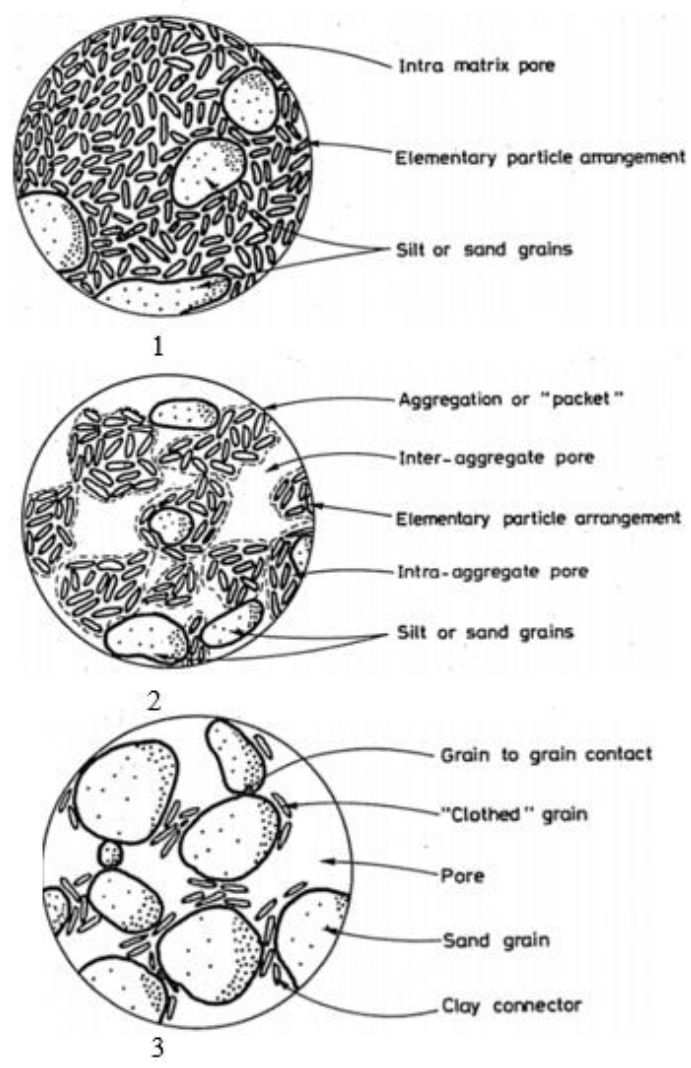

Fig. 2. Types of microfabric. McGrown and Collins (1975) [09]

Clemence and Finbarr (1981) proposed some unstable connection models showed in Figure 3. The first two models are maintained for the capillarity strength between sand-sand, silt-sand, and silt-silt. In the third and fourth, sand grain is clothed by clays. In the fifth the particles are bounded by silt and clay. In the last one, flocculated clay interacts with other through the clay bridge.
The velocity of collapse is related to the bound between grains. In case of capillary suction, the collapse will be immediate; in case of clay buttresses rather slower; and in case of chemical cementing even more slower (Barden et al. 1973 [01]).
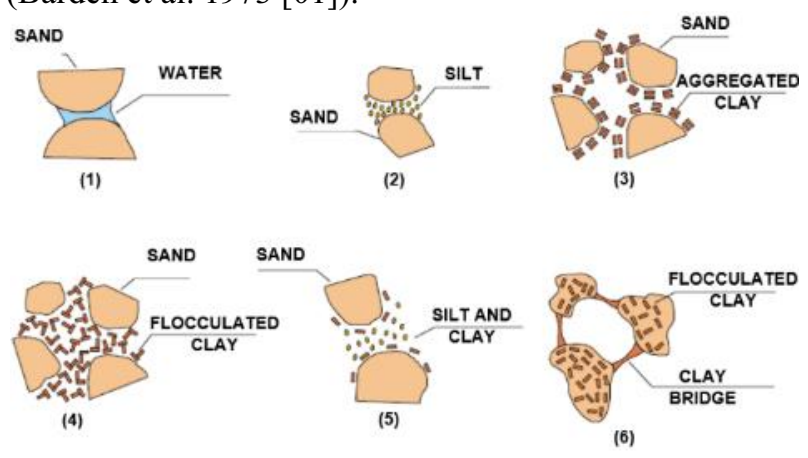

Fig. 3. Main forms of collapsible soil structure. Adapted from Clemence e Finbarr (1981) apud Ferreira (1995) [05]

\section{Materials and methods}

It is possible to study different fabric features through several methods: optical microscope, X-ray diffraction, pore size distribution, wave propagation, dielectric dispersion and electrical conductivity, thermal conductivity, magnetic susceptibility, scanning electron microscope (SEM) and X-Ray computed tomography (CT). The details of each method can be found in Mitchell and Soga (2005) [10]. In this paper, just the two last methods were used.

The CT images were obtained with the thirdgeneration X-ray microtomography system, model NIKON XT H 225 ST. The following parameters were used in the acquisition of the sample: $160 \mathrm{kV}$ tension, 180 $\mu \mathrm{A}$ current and $500 \mathrm{~ms}$ exposure time. A 0.5-mm-thick copper filter was used to minimize low-intensity photons, which cause beam hardening artifacts. The Spatial resolution was $50 \mu \mathrm{m}$. The segmentation process of image was executed in the ImageJ 1.50i (Rasband - NIH) and a detailed prosses can be found in Alves (2019) [11].

The sand from Northeast of Brazil (city of Petrolina) was used in the analysis. A study campaign has been carried out by the group of unsaturated soils at the University of Pernambuco (GÑSAT).

Grain-size tests were performed in the soil (Figure 4). According to the Unified Soil Classification System (USCS) this soil was classified as SM with a coefficient of uniformity 3 and a coefficient of curvature of 1.19 . The optimum water content was about $7 \%$ with a dry density of $18.3 \mathrm{kN} / \mathrm{m}^{3}$ (Santos 2018 [12]). The natural density of the soil ranged between 14.97 to $15.10 \mathrm{kN} / \mathrm{m}^{3}$ (Torres 2014 [13]).

The potential of collapse (PC) (Equation 1) varies with the confinement and grow until $4.64 \%$ at $160 \mathrm{kPa}$, and decreases until $3.59 \%$ for the pressure of $1280 \mathrm{kPa}$. The oedometer test for undeformed samples is shown in Figure 5.

$$
P C(\%)=\frac{\Delta H}{H 0} \times 100
$$


Where: $\Delta \mathrm{H}$ means the change of height and $\mathrm{H}_{0}$ the initial height of the sample.

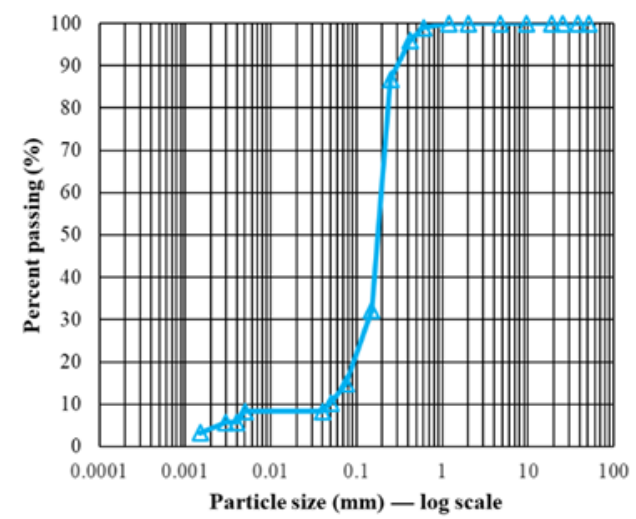

Fig. 4. Grain-size distribution. From Torres 2014 [13]

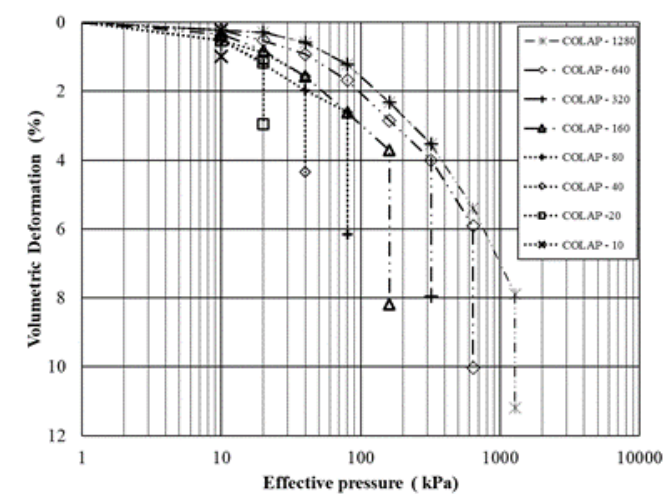

Fig. 5. Oedometer compressibility test of Petrolina's soil. From Torres 2014 [13]

The strength of Petrolina's soil varied with suction degree, density, and confinement. The friction angle varied from $28^{\circ}$ to $34^{\circ}$ and the cohesion from 0 to $25 \mathrm{kPa}$ (Freitas 2017 [04], Santos 2018 [12]). During the collapse there was a significant reduction in the strength, but with the strain this resistance was partially recovered (Figure $6)$.

Horizontal stress was studied by Santos (2018) [12] and ranged significantly with the application of pressure. On the other hand, in the steady state the values of $\mathrm{K}_{0}$ ranged from 0.21 to 0.39 .

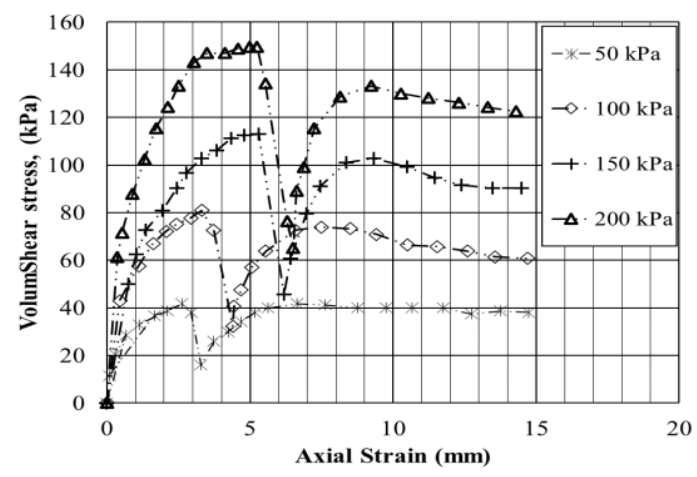

Fig. 6. Direct shear tests with collapse. From Santos (2018) [12].

\section{Sample acquisition and preparation for fabric analysis}

Five samples of Petrolina's soil were cut from undisturbed monolith $(0,30 \times 0,30 \times 0,30 \mathrm{~m})$. Theses samples were prepared according to test requirements. For the Scanning Electron Microscopy (SEM) two undeformed samples (SP1 and SP2) of $75 \mathrm{~mm}$ of diameter and $20 \mathrm{~mm}$ of height were cut from the block. The two cylinders were consolidated to a pressure of $160 \mathrm{kPa}$ in oedometer compressibility test, which were carried out following the Brazilian standard (NBR 16853 (2020) [14]). The SP2 was saturated with distilled water to develop collapse. After that, the samples were unloaded and dried naturally. The samples were carefully removed from the metal ring, and then a cube of $1 \mathrm{~cm}$ was extracted from the center of the circumference. Finally, the samples were metalized with graphite and analyzed in the SEM.

Two samples for computed tomography (SP3 and SP4), were similarly prepared, consolidated to a pressure of $160 \mathrm{kPa}$ in oedometer compressibility test. SP4 sample was saturated, and then both samples were unloaded and dried naturally. Samples were kept in the cylinder. For the undisturbed sample (SP5), it was used a PVC cylinder of $75 \mathrm{~mm}$ diameter and $100 \mathrm{~mm}$ height.

\section{Results}

The CT enables the analysis of sample interior, however with worse resolution. On the other hand, although SEM provides a better resolution, it only enables the analysis of the sample's surface. These methods are discussed below.

\subsection{Computed Tomography}

In the grayscale image (Figure 7), the black pixels represent the void in the soil. In the undisturbed sample the soil structure shows large pores (bigger than $10 \mathrm{~mm} x$ $0.5 \mathrm{~mm}$ ) which represent biopores (Figure 7 - a). Using a pressure above $160 \mathrm{kPa}$, the soil structure changed and the macroporosity reduced (Figure $7-\mathrm{b}$ ). The imposed collapse resulted in a rearrangement among the grains due to cementation's breakdown of clay particles and a densification of the soil (Figure 7 - c)

Pores in 3D are represented in Figure 8 and small isolated pores were excluded to facilitate visualization. It is possible to visualize many connected macropores in Figure $8-\mathrm{a}$, as it is an undisturbed sample, concluding that the central part of SP5 maintained its original arrangement state. The macropores in SP4 (Figure $8-b$ ), presented a reduction in size and connectivity after the compression applied, turning them in isolated and smaller pores. In Figure $8-\mathrm{c}$, there are much smaller pores, however there are still some macropores, which reveals the existence of instability, and the risk of a further collapse in a smaller dimension, as reported by Alonso (2012) [15]. 


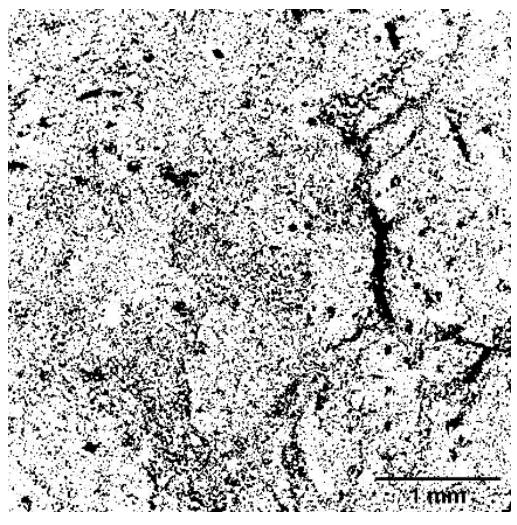

(a)

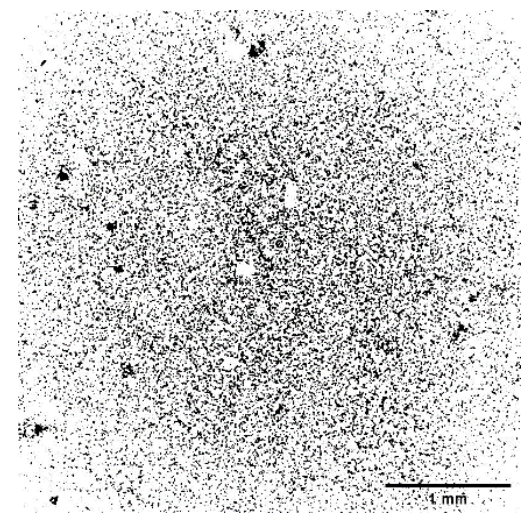

(b)

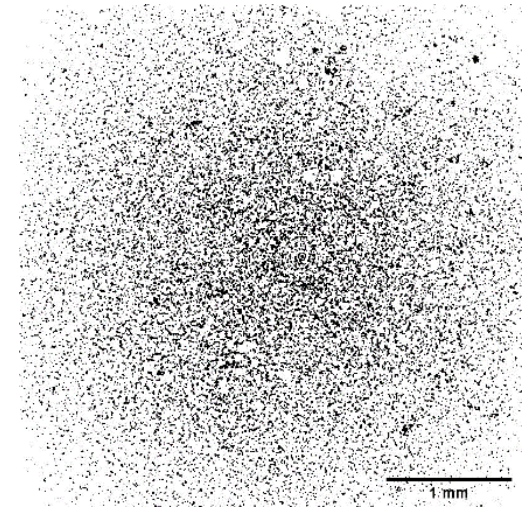

(c)

Fig. 7. Slice of (a) undisturbed sample, (b) after compression process and (c) after collapse process.

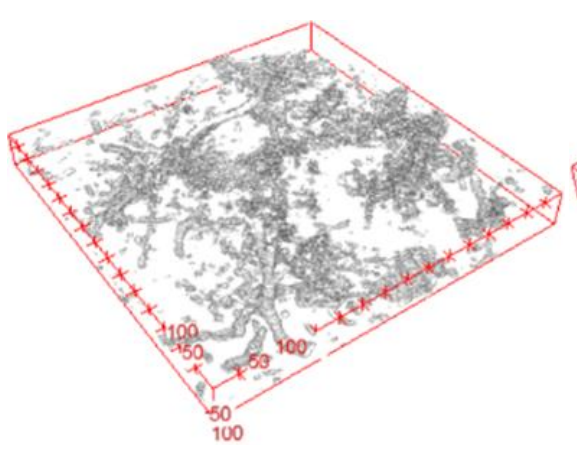

(a)

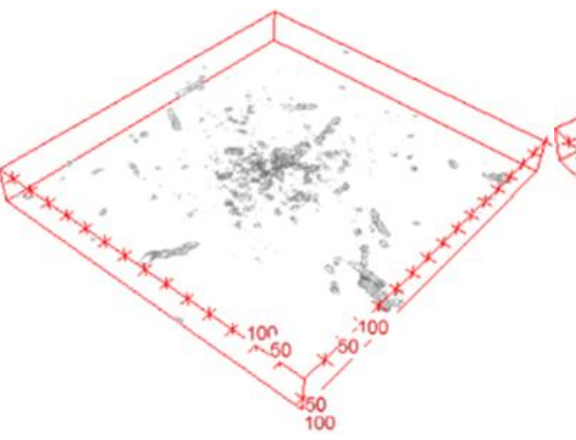

(b)

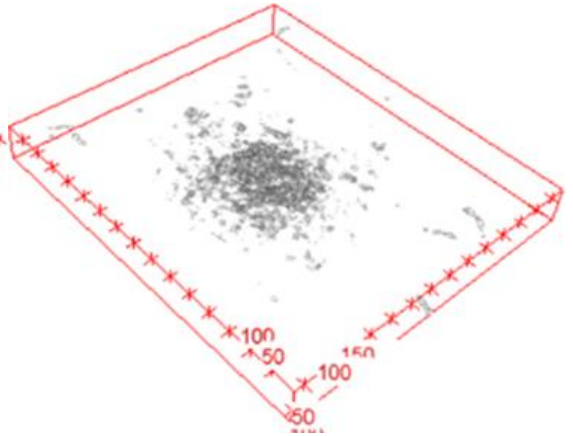

(c)

Fig. 8. Connected micropores of (a) undisturbed sample, (b) after compression process and (c) after collapse process.

The spatial variability of the soil matrix (average radiodensity in each section) can provide a qualitative assessment of the total porosity and the material type of the sample. For this analysis, a volume of 20x40x40 mm in the central part of the specimens was chosen for the spatial variability studies. For better representativeness of the sample $5 \mathrm{~mm}$ in the top of SP3 and SP4 were excluded, due to the volumetric deformation of the oedometer compression test. The result is shown in Figure 9. It is observed that SP5 has a less dense structure than SP3 and SP4. SP4 presented the greatest density, is the densest of all, which was expected due to compression and collapse.

The decrease of density in the top parts of SP3 and SP4 is observed, likely due to the elastic recovery of the soil in the mobile part of the oedometer cell, This behavior is not so pronounced in depth between 12.5 and $17.5 \mathrm{~mm}$, where SP3 is denser than SP4. This is probably due to the presence of some pore that was not affected by the collapse in SP4 or the existence of big quartz grains in $\mathrm{SP}$, which affects the average radiodensity.

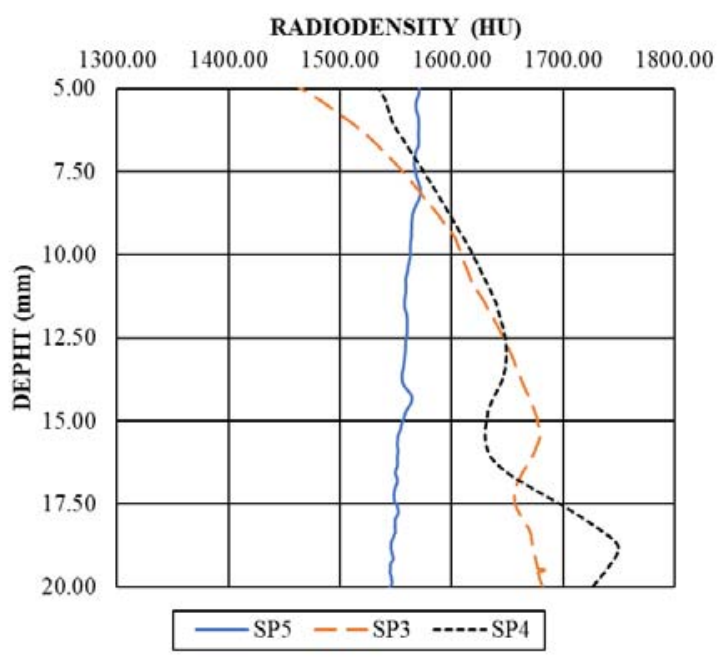

Fig. 9. Radiodensity. 


\subsection{Scanning electron microscopy}

The microstructural characterization of the undeformed sample is illustrated in the electron micrographs of Figure 10 (a), the overall fabric, and Figure 10 (b) the particle arrangement. The figures revealed an open fabric and a simple packaging structure of sands covered by a small amount of clay that almost always forms clay bridges between them and can create a potential instability at intergranular contacts by the addition of water. (Freitas (2017) [4]).

The electron micrographs of Figure 11 illustrate the different soil arrangements after the compression process under the pressure of $160 \mathrm{kPa}$ and unloaded to zero pressure, with a positive volume change of $0.41 \%$. Despite all the effects of the sample preparation process (strain relief, cutting, among others), it was observed that the soil structure after loading (Figure 11 - a) was similar to the undisturbed sample of natural soil (Figure $10-a$ ). The soil matrix consisted in an intense amount of sand grains and little clay (Figure $11-b$ ).

The grains of sand were quartz in varied sizes and sub-rounded and sub-angular shapes. The application of the pressure of $160 \mathrm{kPa}$ caused deformation in the soil and reduction of the voids between grains. There was a denser packing between grains, caused by pressure application. The soil's microstructure was unstable, and the grains of sand were clothed with illuvial clay.

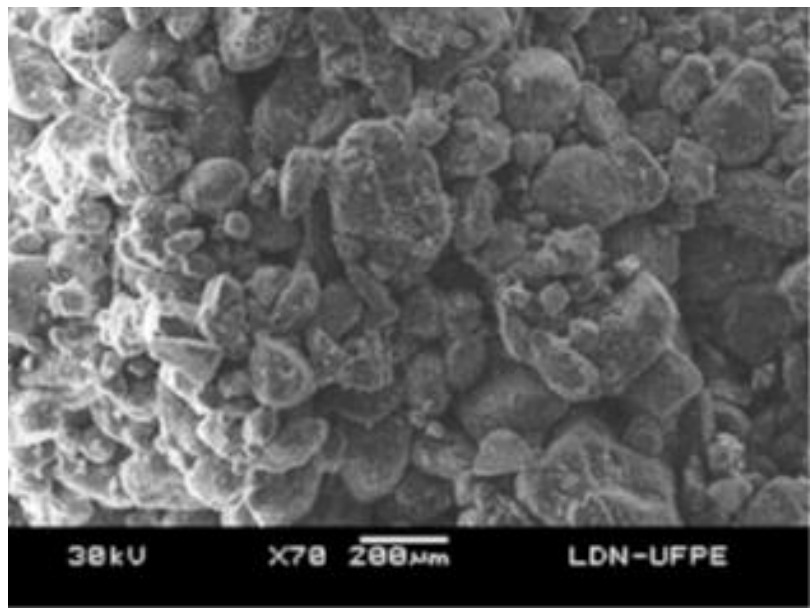

(a)

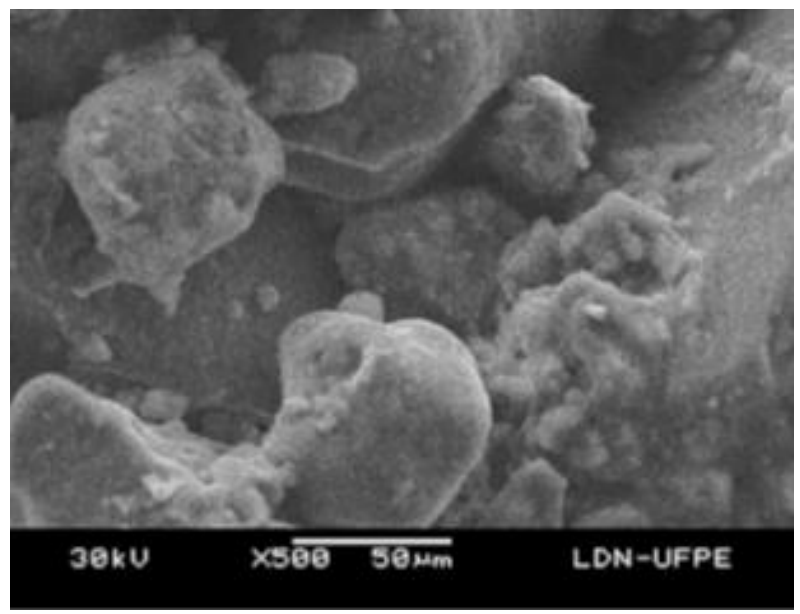

(b)

Fig. 10. Electron micrograph of undisturbed sample (a) overall fabric (b) microstructural arrangement. From Freitas (2017) [4].

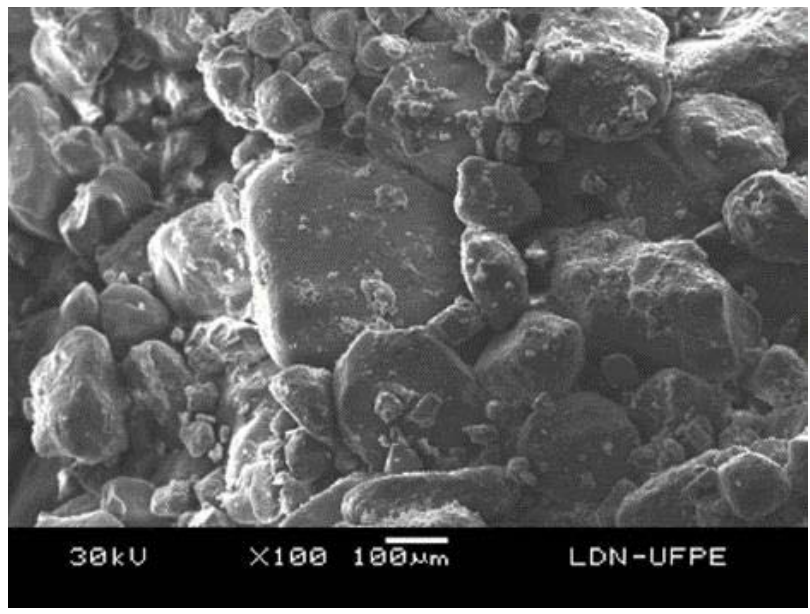

(a)

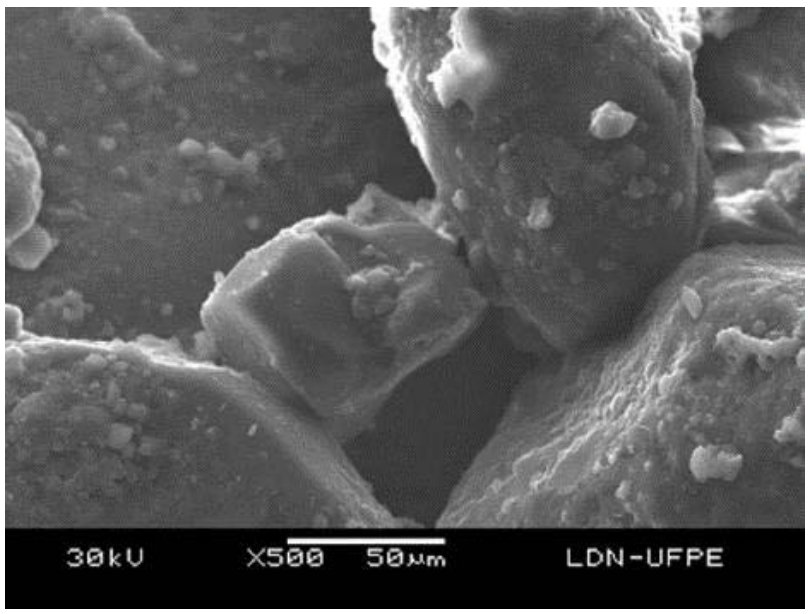

(b)

Fig. 11. Electron micrograph of soil arrangements after the compression process under the pressure of $160 \mathrm{kPa}$ and unloaded to zero pressure (a) overall fabric (b) grain-grain contacts. 


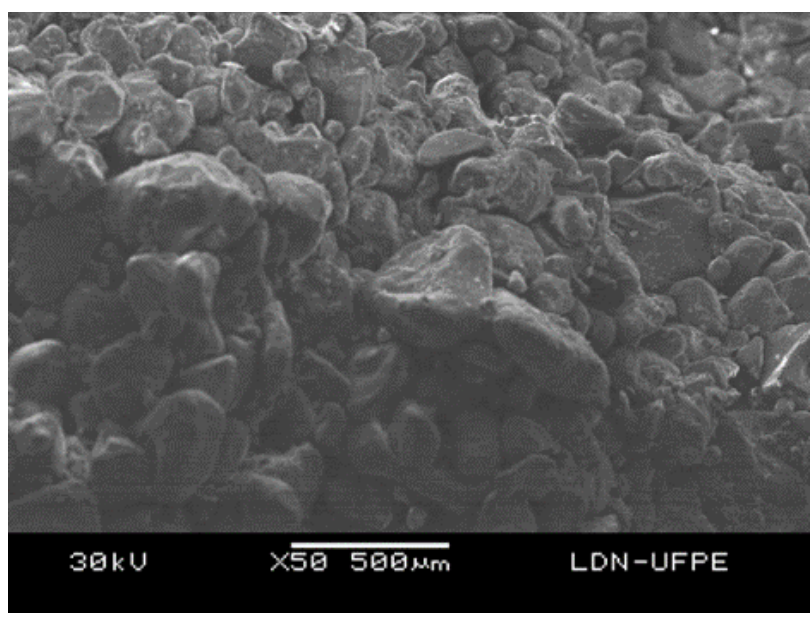

(a)

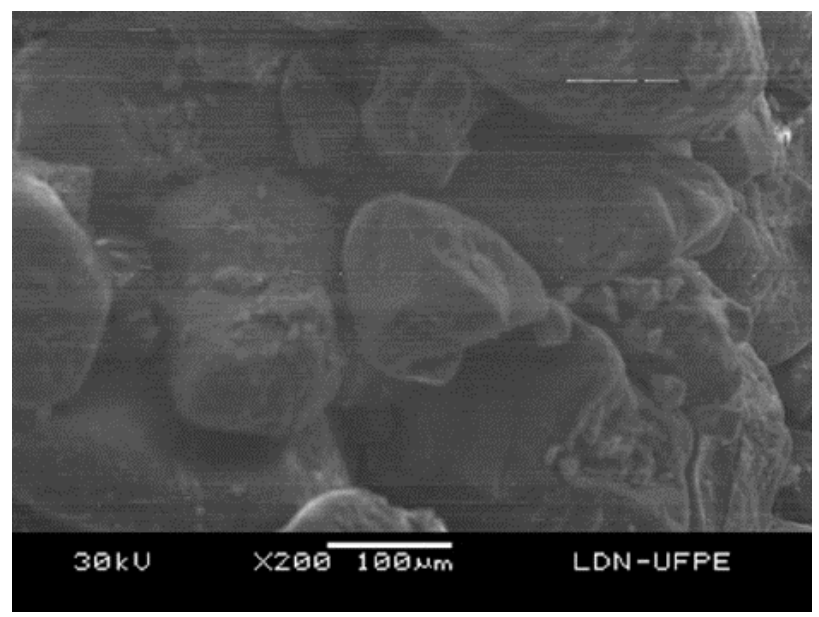

(b)

Fig. 12. Electron micrograph of soil arrangements after the compression and collapse process. (a) overall fabric (b) microstructural arrangement.

Electron micrographs shown in Figure 12 illustrate different soil arrangements after the compression and collapse process under the pressure of $160.00 \mathrm{kPa}$ and unload to zero pressure with a positive volume change of $0.65 \%$. As previously mentioned, despite all the effects of the sample preparation process (drying, strain relief, cut among others), it was observed that the soil structure after collapse was similar to the undisturbed sample of natural soil and the sample compressed to $160 \mathrm{kPa}$. There was a greater packing between grains, caused by the application of pressure and collapse (Figure 12 - a). The microstructure of the soil (Figure 12 - b) was still unstable because the grains of sand were clothed with illuvial clay.
The water percolation caused a wetting-induced softening of the clay particles.

A schematic view of the different fabric and the oedometer test are shown in the Figure 13. The undisturbed sample (Figure 13 - b) has a void ratio of 0.626 and a specific density of $16.19 \mathrm{kN} / \mathrm{m}^{3}$. After oedometer compression, the sample has a void ratio of 0.574 and a specific density of $16.73 \mathrm{kN} / \mathrm{m}^{3}$ (Figure 13 c). The collapse process made a denser soil, with a void ratio of 0.479 and a unit weight of $17.61 \mathrm{kN} / \mathrm{m}^{3}$ (Figure $13-d)$.

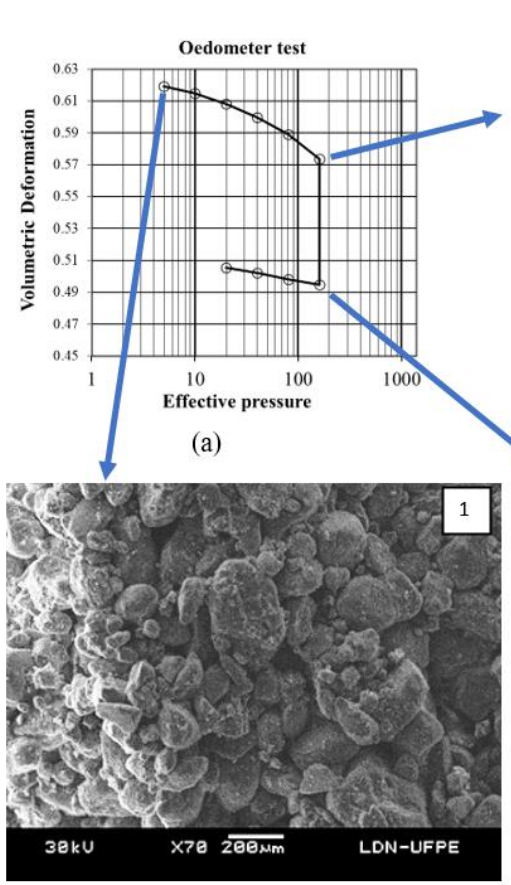

(b)

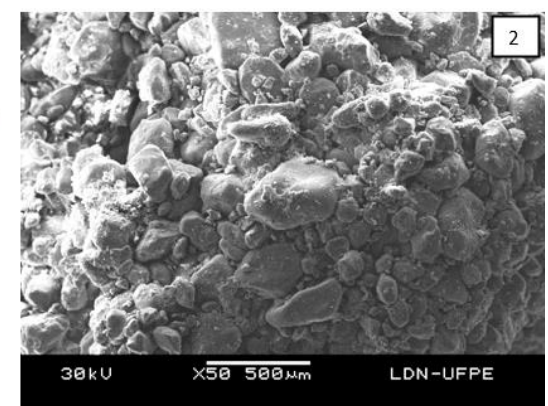

(c)

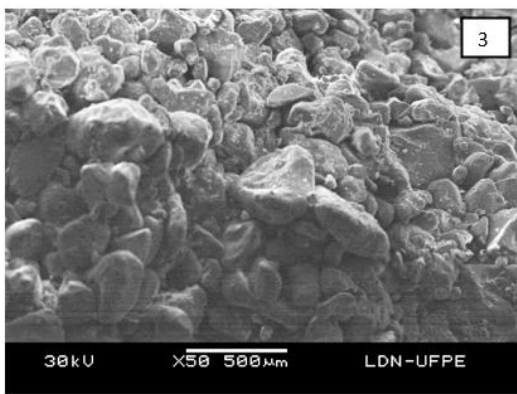

(d)

Fig. 13. Schematic view of different soil arrangements with the Electron micrograph (a) oedometric graphic (b) undisturbed sample (c) soil arrangements after the compression process under the pressure of $160 \mathrm{kPa}$ and unloaded at zero pressure (d) after the compression and collapse process. 


\section{Conclusions}

In this study, Petrolina's sand was scanned using a X-ray computed tomography and scanning electron microscopy. According to the results of this work, the following conclusions can be reasonable:

- The soil microstructure was a matrix with predominance of sand grains clothed with illuvial clay, which gives the character of instability.

- The X-Ray Computed Tomography allows construction of a three-dimensional profile inside a material and it is an important tool to study the macro fabric of the soil. This noninvasive technique showed that there was a reduction of macropores with loading of Petrolina's sand soil. It was also possible to analyze by radiodensity that the interior of the soil sample in the expands in a nonregular way, being more pronounced oedometrer cell in the top of the sample. That behavior showed that the soil cannot be treated as homogeneous structure (continuum theory).

- Even after the collapse, Petrolina's sand still presents some macropores, which reveals the existence of instability, and the risk of a further collapse in a smaller dimension.

- The scanning electron microscope allow to observe with a good resolution the simple packing arrangement of Petrolina's sand in the three samples.

- After loading and collapse, the structure was remained of simple packing arrangement in both cases, however, there was a greater packing between the grains in addition to wetting-induced softening of the clay particles.

- The intergranular bonding is a complex problem, but this propriety is important for most engineering analysis, because strength, compressibility, and permeability depend on size, shape, and arrangement of particles.

- The two microstructure analysis techniques are complementary. The TC allows construction of a threedimensional density profile inside the material. The SEM allows direct observation of particles, particle groups and pore space.

\section{Acknowledgements}

The authors are thankful to the support received during the development of this work from DEN/UFPE and CNPq.

\section{References}

1. Ll. BARDEN, A. MCGOWN, K. COLLINS (1973). The collapse mechanism in partly saturated soil. Engineering Geology, v. 7, n. 1, p. 49-60.

2. K. Schwartz (1985). Collapsible soils: Problems of soils in South Africa - State-of-the-art. The Civil Engineer in South Africa, 27: 379-393
3. O.M. VILAR \& R.A. RODRIGUES (2015). Revisiting Classical Methods to Identify Collapsible Soils. In: Soils and Rocks, 38 (3), p.265-278.

4. M. L. R. A. FREITAS (2017). Comportamento geomecânico de um solo colapsível de Petrolina-PE avaliado por meio de ensaios de campo e laboratório. Dissertation.

5. S. R. M. Ferreira (1995). Colapso e expansão de solos naturais não saturados devido à Inundação. Doctoral Thesis.

6. M. VARGAS (1978). Introdução à Mecânica dos Solos. 1. ed.

7. M. J. R. D. SILVA (2003). Comportamento geomecânico de solos colapsíveis e expansivos em Petrolina-PE: cartas de suscetibilidade. Dissertation.

8. R. A. RODRIGUES \& J. A. LOLLO (2008). Características dos Solos Colapsíveis. In: Solos Colapsíveis: identificação, comportamento, impactos, riscos e soluções tecnológicas. UNESP, São Paulo, Cap. 2, p.59-67.

9. A. MCGOWN, K. COLLINS (1975). The microfabrics of some expansive and collapsing soils. p. 323-332.

10. J. K. Mitchell \& K. Soga (2005). Fundamentals of soil behavior (Vol. 3). New York: John Wiley \& Sons.

11. I. S. Alves (2019). Análise microestrutural e numérica de um solo colapsível antes e após o colapso Dissertation.

12. B. N. A. Santos (2018). Análise da Resistência ao Cisalhamento e Coeficiente de Empuxo no Repouso Durante a Inundação em Solo Colapsível de Petrolina - PE. Dissertation.

13. M. S. Torres (2014). Avaliação da Colapsibilidade e da Resistência de Ponta de um Solo de Petrolina Devido a Inundação. Dissertation.

14. Associação Brasileira de Normas Técnicas (2020). Solo - Ensaio de Adensamento Unidimensional Método de ensaio - NBR 16.853. Rio de Janeiro.

15. E. E. ALONSO (2012). Unsaturated Soils: basic concepts and applications (Part 1 and Part 2). Disponível em: https://www.issmge.org/education/recordedwebinars/unsaturated-soils-basic-concepts-andapplications-part-1-and-part-2. Access: 23 sep. 2020. 